\title{
MicroRNA-155 in Patients with Chronic Stable Angina
}

\author{
Mohamed M Elshafae', Jehan H Sabry ${ }^{1}$, Mohamed A Salem², Hanan M Elshafee \\ ${ }^{1}$ Clinical and Chemical Pathology Department, Faculty of Medicine, Benha University, Egypt. \\ ${ }^{2}$ Cardiology Department, Faculty of Medicine, Benha Universityz, Egypt.
}

\begin{abstract}
Background: Atherosclerotic cardiovascular disease is a chronic inflammatory disease and one of the major causes of death worldwide. MicroRNAs are associated with many physiological and pathological situations as inflammation and cardiovascular disease. The communication between microRNAs, inflammation, and atherosclerosis, drive attention to the possibility that inflammation-related microRNAs, miRNA-155, could have a role in atherosclerosis progression.

Objectives: We aimed to determine the levels of circulating miRNA-155 in chronic stable angina patients and to study the impact of microRNA-155 on coronary artery disease severity and extent.

Methods: MicroRNA was extracted and assessed from plasma of 50 subjects ( 20 normal controls and 30 patients with chronic stable angina) using quantitative reverse-transcription PCR (RT-PCR). Levels were compared in the two groups and correlated with Gensini score in the group with chronic stable angina (CSA).

Results: Plasma levels of microRNA 155 were significantly lower in CSA patients $(0.59 \pm 0.48,1.94 \pm 0.76$, in patients and control group respectively $(\mathrm{P}<0.001)$. The expression of miR-155 correlated negatively with Gensini scores $(\mathrm{P}<0.001)$, total cholesterol $(\mathrm{P}<0.001), \mathrm{LDL}-\mathrm{c}$ $(\mathrm{P}=0.002)$ and triglycerides $(\mathrm{P}=0.03)$. There was a significant difference in miRNA-155 levels among the quartiles of the CSA group ( $<$ $0.001)$ denoting negative correlation between microRNA 155 and coronary artery disease extent. ROC curve showed that microRNA-155 sensitivity and specificity for the prediction of severity of atherosclerosis were $86.67 \%$ and $80 \%$ respectively.
\end{abstract}

Conclusion: Plasma miRNA-155 is significantly lower in CSA angina patients and levels significantly decreases with the progression of atherosclerosis.

Keywords: Micro RNA 155, CSA, Gensini score, Atherosclerosis, Reverse-Transcription PCR.

\section{Introduction}

Coronary artery disease (CAD), secondary to coronary atherosclerosis, is the most common type of cardiovascular disease and leading cause of death globally. Understanding the underlying molecular and cellular mechanisms may contribute to the prevention of cardiovascular diseases ${ }^{1}$. Atherosclerosis is a chronic inflammatory disease characterized by the accumulation of lipids and inflammatory cells in the vessel wall. Inflammation and immune responses play an axial function in all atheroscleroticphases starting from preface of the fatty streak ending in acute coronary syndromes (ACS) eruption ${ }^{2}$. MicroRNAs (miRNA-155) are small noncoding RNA molecules that negatively regulate gene expression by triggering either translation repression or RNA degradation ${ }^{3}$. They are leading components for many cellular processes. MicroRNA expression was described to betissue-specific, firmly adjusted during embryogenesis, and overexpressed/underexpressed in different pathologies, including cardiovasculardiseases ${ }^{4}$. To date, about 2000 microRNAs have been detected. Human genome consist of large number of microRNA genes accounting for 1-5\% of all predicted human genes and mammalian microRNAs are known to regulate approximately $30 \%$ of all protein- coding genes ${ }^{5}$. MicroRNA155 is widely expressed in various cells, such as T cells, Bcells, mononuclear cells and endothelial cells. As a multifunctionmicro RNA, it is extensively involved with the differentiation, proliferation and apoptosis of many cells, and the development of many tissues.

MiRNA-155 can inhibit inflammatory response and affect lipid uptake in macrophages through regulating othertargets $^{6}$. In this study the levels of circulating microRNA-155 in patients with chronic stable angina were measured. In addition, the impact of microRNA155 on the severity and extent of coronary artery disease was evaluated.

\section{Material and methods}

Study Design: This observational cross-sectional study included fifty persons who were enrolled for coronary angiography due to suspicion of coronary artery disease at Cardiac Catheterization Unit, Department of cardiology, Benha University Hospital from february 2016 until august 
2016. All investigations and research work were done in the Clinical and Chemical pathology departement, Benha University Hospital. Subjects were categorized into the following groups; patient group (30 patients who had chronic stable angina based on clinical history and results of coronary angiography) and control group (20 persons who had normal coronary angiography).

Inclusion Criteria Were: Patients with suspicion of stable angina who were referred for coronary angiography based on one or more of the following indications: 1- Patients who have high pretest probability and severe symptoms. 2-Patients with reduced LVEF $<50 \%$ and typical angina. 3- Patients with positive findings at non-invasive risk stratification studies.

Exclusion Criteria Were: Evidence of acute coronary syndrome, left ventricular ejection fraction $\leq 30 \%$, subject receiving or scheduled to receive chemotherapy of malignancy, subject receiving immunosuppressant therapy and/or has known immunosuppressive or autoimmune disease, patients with acute or chronic inflammatory disorders, subject with documented or suspected liver disease, known renal insufficiency. The study was approved by the Local Ethics Committee and all study participants gave a written informed consent before enrollment .

I Baseline Evaluation: Baseline evaluation included review of medical history including demographic data (age, sex) and risk factors of CAD (diabetes mellitus, hypertension and smoking), analysis of cardiac symptoms, cardiac medications and comorbidities, clinical examination and 12- lead ECG were done.

II Coronary angiography (All patients underwent elective coronary angiography using standard Judkin's technique by femoral approach ${ }^{7}$. Each major epicardial vessel was visualized in at least two orthogonal projections to detect the degree of luminal stenosis; percent diameter stenosis was determined by using quantitative coronary angiography (QCA).

Ginsini score (GS) calculation: The Gensini score (GS) was used in the present study to assess the burden of coronary atherosclerosis. This was done as described by Gensini GG in (1983): [The GS system yields a qualitative and quantitative evaluation of the coronary angiogram. The score grades the narrowing of the lumen of the coronary artery as: 1 for $\leq 25 \%$ narrowing, 2 for $26-50 \%$ narrowing, 4 for $51-75 \%$ narrowing, 8 for $76-$ $90 \%$ narrowing, 16 for $91-99 \%$ narrowing and 32 for total occlusion. Next, this primary score was multiplied by a factor that took into account the importance of the position of the lesion in the coronary arterial tree: 5 for the left main coronary artery, 2.5 for the proximal left anterior descending artery (before $1^{\text {st }}$ septal branch) or proximal left circumflex artery (before $1^{\text {st }}$ obtuse marginal branch), 1.5 for the mid-region of left descending artery or left circumflex artery, 1 for the distal left anterior descending artery, and 1 for the mid or distal region of the left circumflex artery or right coronary artery $]^{8}$.

Blood samples: Five milliliters of venous blood samples were withdrawn from each participant via antecubitalvenipuncturing into EDTA- containing tubes. Samples were centrifuged at $1,200 \mathrm{X} g$ for 10 minutes at $4^{\circ} \mathrm{C}$. Plasma were collected and centrifuged again at 12,000 $\mathrm{X} g$ for 10 minutes at $4{ }^{\circ} \mathrm{C}$. The clear plasma obtained was aliquoted and frozen at $-80^{\circ} \mathrm{C}$ until used for lipid profile analysis and miRNA extraction.

\section{Detection of miRNA-155 by real time reverse transcription polymerase chain reaction (RT-PCR) was performed as follows}

1- RNA extraction:- Using the miRNeasy Mini Kit Qiagen according to the manufacturer's instruction RNAs were extracted from plasma samples. $200 \mu \mathrm{L}$ of splasma were mixed with $1000 \mu \mathrm{L}$ Qiazollysis reagent and incubated for 5 minutes at room temperature. Then $200 \mu \mathrm{L}$ of chloroform were added and the tube was vortexed vigorously for 15 seconds. After $3 \mathrm{~min}$ incubation at room temperature, the tube was centrifuged at $12,000 \mathrm{X} \mathrm{g}$ for $15 \mathrm{~min}$, in which the sample separated into 3 phases. $350 \mu \mathrm{L}$ of the upper aqueous phase was transferred into new collection tube and mixed with $900 \mu \mathrm{L}$ of $100 \%$ ethanol. About $700 \mu \mathrm{L}$ of the sample were pipetted into an RNeasy Mini Spin column in a $2 \mathrm{ml}$ collection tubes and centrifuged at $800 \mathrm{X} \mathrm{g}$ for I5 Sec. at room temperature. Then the flow through was discarded. Specimen was washed three times with $700 \mu$ of RWT buffer and $500 \mu$ l of RPE Buffer respectively through centrifugation at $8000 \mathrm{X} g$ for $15 \mathrm{sec}$. Finally RNA was eluted using $50 \mu \mathrm{L}$ R Nase-free water after centrifugation for $1 \mathrm{~min}(\geq 8000 \mathrm{Xg})$.

2- Reverse transcription:- Using the miScript II RT Kit according to the manufacturer's instruction extracted RNA was reverse-transcribed into cloned DNA. The reverse transcription master mix were prepared on ice as follows: 2 $\mu \mathrm{L}$ of $10 \mathrm{x}$ mi Script Nucleics, $4 \mu \mathrm{L}$ of $5 \mathrm{x}$ mi Script Hispec buffer, $7 \mu \mathrm{L}$ of RNase-free water, $2 \mu \mathrm{L}$ of mi Script Reverse Transcriptase Mix and $5 \mu \mathrm{L}$ of Template RNA. The total volume was $20 \mu \mathrm{L} /$ reaction. Template RNA were Added to each tube containing reverse transcription master mix. Then mixed gently, briefly centrifuged, incubated for 60 $\mathrm{min}$ at $37^{\circ} \mathrm{C}$, then incubated for $5 \mathrm{~min}$ at $95^{\circ} \mathrm{C}$ to inactivate miScript reverse transcriptase mix in Veriti thermal cycler applied biosystem.

e-ISSN: 2349-6991; p-ISSN: 2455-0396 
3- RNA quantification: PCR quantification was performed with PCR (Step One real time PCR, Applied Biosystem ) PCR was performed using miScript SYBR Green PCR Kit supplied by (QIAGEN) according to manufacturer instructions. The primers for micro RNA155 and housekeeping gene were supplied by Qiagene. Fluorescene measurements were made in every cycle. The cycling conditions used were as follows: PCR initial active stepat $95^{\circ} \mathrm{C}$ for $15 \mathrm{~min}$, then 40 cycles which includes denaturation at $94^{\circ} \mathrm{C}$ for $15 \mathrm{~s}$, annealing at $55^{\circ} \mathrm{C}$ for $30 \mathrm{~s}$ then extension at $70^{\circ} \mathrm{C}$ for $30 \mathrm{~s}$. The normalization control used was SNORD 68.StepOne software was used for quantification and expression of miRNA 155 as relative miRNA level compared with a SNORD68 gene according to the $2^{-\Delta \Delta \mathrm{Ct}}$ method ${ }^{9}$.

Statistical analysis : The collected data were summarized in terms of mean \pm Standard Deviation (SD) and range for quantitative data and frequency and percentage for qualitative data. Comparisons among the different study groups were performed using the Chi-square test $\left(\chi^{2}\right)$ and Fisher's Exact Test (FET) to compare proportions as appropriate. The Student t-test ( $\mathrm{t}$ ) was used to detect mean difference between two groups regarding parametric data and the Mann-Whitney test (z) was used to compare two non-parametric data. Comparisons between more than two groups were carried out using the Kruskal Wallis test $\left(\chi^{2}\right)$ regarding non-parametric data. The Spearman correlation coefficient (rho; $\rho$ ) was used to test the correlation between micro RNA-155 levels and studied parameters. Receiver Operator Curve (ROC) analysis of micro RNA-155 as a diagnostic test for stable angina patients was carried out and the Area Under the Curve (AUC), the best cut off point and the corresponding sensitivity and specificity were determined. The corresponding P-values were obtained. A P-value $<0.05$ was considered statistically significant (S), a P-value $<0.001$ was considered statistically highly significant (HS), while a P-value $>0.05$ was considered statistically non-significant. The statistical analysis was conducted using STATA/SE 11.2 for Windows (STATA Corporation, College Station, Texas).

\section{Results}

Study Population: The mean age was $54.56 \pm 10.26$ years $(57.57 \pm 9.35,53.05 \pm 8.01$, in patients and control group respectively. $\mathrm{P}=0.08) .54 \%$ of the study population were males (63\% vs $54 \%$ in patients' and control groups respectively, $\mathrm{P}=0.10)$ and $46 \%$ were females (37\% vs $60 \%$ in patients' and control groups respectively, $\mathrm{P}=0.10) .50 \%$ of the study population were hypertensive (57\% vs $40 \%$ in patients' and control groups respectively, $\mathrm{P}=0.25$ ). Persons with history of diabetes mellitus represented $50 \%$ of the study population $(47 \%$ vs $55 \%$ in patients' and control groups respectively, $\mathrm{P}=0.56) .18 \%$ of the study population were smokers ( $23 \%$ vs $10 \%$ in patients' and control groups respectively, $\mathrm{P}=0.12)$ [Table 1 ].

II Baseline investigations: The mean total cholesterol was $163.5 \pm 30.18 \mathrm{mg} / \mathrm{dl}(166.93 \pm 31.27 \mathrm{mg} / \mathrm{dl}, 158.35 \pm 28.74$ $\mathrm{mg} / \mathrm{dl}$ in patients' and control groups respectively. $\mathrm{P}=$ $0.33)$. Mean triglycerides level was $146.04 \pm 45.46 \mathrm{mg} / \mathrm{dl}$ $(142.83 \pm 45.2 \mathrm{mg} / \mathrm{dl}, 150.85 \pm 46.6 \mathrm{mg} / \mathrm{dl}$ in patients' and control groups respectively, $\mathrm{P}=0.55$ ). The LDL-c was 86.4 $\pm 29.97 \mathrm{mg} / \mathrm{dl}(91.45 \pm 29.39 \mathrm{mg} / \mathrm{dl}, 78.83 \pm 29.95 \mathrm{mg} /$ $\mathrm{dl}$ in patients' and control groups respectively. $\mathrm{P}=0.15)$. HDL-c was $47.86 \pm 7.84 \mathrm{mg} / \mathrm{dl}(46.87 \pm 7.88 \mathrm{mg} / \mathrm{dl}, 49.36$ $\pm 7.73 \mathrm{mg} / \mathrm{dl}$ in patients' and control groups respectively. $\mathrm{P}=0.28)$. The ejection fraction was $59.94 \pm 8.4 \%(60.97$ $\pm 8.26 \%, 58.4 \pm 8.57 \%$ in patients' and control groups respectively. $\mathrm{P}=0.29$ )[Table 2 ].

III Coronary angiography in patients with chronic stable angina: The mean Gensini score was $36.23 \pm 26.86$

IV MicroRNA 155 in study population: The mean level was $1.13 \pm 0.9(0.59 \pm 0.48,1.94 \pm 0.67$ in patients' and control groups Respectively, $\mathrm{P}<0.001)$ [Figure 1].

V Micro RNA 155 and Gensini score: We reported a strong negative correlation between the level of microRNA 155 and the Gensini score $(\mathrm{r}=-0.87, \mathrm{P}<0.001)$ [figure $2]$. On dividing the case study group into four quartiles according to Gensini score there was a statistically significant gradual downregulation in microRNA 155 (P value $<0.001)$ with significant decrease in the third and fourth quartiles compared with the first quartile group $(p<0.001)$ and significant decrease in the fourth quartile compared with the second quartile group[Table 3].

VI Correlation between microRNA 155 and study variables: When analyzing the correlation between proatherogenic risk factors and microRNA 155, we found that microRNA 155 correlated negatively with total cholesterol levels $(r=-0.60, \mathrm{P}<0.001)$, LDL-c $(\mathrm{r}=-55, \mathrm{P}=$ $0.002)$ and triglycerides $(\mathrm{r}=-0.39, \mathrm{P}=0.03)$ [table 4].

VII Diagnostic performance of Micro RNA 155 for atherosclerosis: Roc curve analysis of microRNA 155 for the prediction of severity of coronary atherosclerosis shows $86.67 \%$ sensitivity and $80 \%$ specificity with $87 \%$ positive predictive value and $80 \%$ negative predictive value and the area under the curve was 0.9567 and best cutoff point value of 1.43 suggesting that microRNA 155 may act as a marker of severity of atherosclerosis [Figure 3]. 
Table 1: Base line characteristics of the study population.

\begin{tabular}{|c|c|c|c|c|c|c|c|c|c|}
\hline \multirow{2}{*}{\multicolumn{2}{|c|}{$\begin{array}{c}\text { Variable } \\
\text { No. }\end{array}$}} & \multirow{2}{*}{\multicolumn{2}{|c|}{$\begin{array}{c}\text { Cases } \\
(\text { no. }=30)\end{array}$}} & \multirow{2}{*}{\multicolumn{2}{|c|}{$\begin{array}{l}\text { Controls } \\
(\text { no. }=20)\end{array}$}} & \multirow{2}{*}{\multicolumn{2}{|c|}{$\begin{array}{c}\text { Total } \\
(\mathrm{no}=50)\end{array}$}} & \multirow{4}{*}{$\begin{array}{c}\text { Test } \\
t=1.77\end{array}$} & \multirow[t]{2}{*}{$\mathrm{P}$} \\
\hline & & & & & & & & & \\
\hline & & 10 & & 70 & IVO. & 10 & & & \\
\hline $\begin{array}{c}\text { Age } \\
\text { (years) }\end{array}$ & $\begin{array}{c}\text { Mean } \pm S D ; \\
\text { range }\end{array}$ & \multicolumn{2}{|c|}{$\begin{array}{c}57.57 \pm 9.35 \\
(40-77)\end{array}$} & \multicolumn{2}{|c|}{$\begin{array}{c}53.05 \pm 8.01 \\
(30-61)\end{array}$} & \multicolumn{2}{|c|}{$\begin{array}{c}54.56 \pm 10.26 \\
(30-77)\end{array}$} & & 0.08 \\
\hline \multirow{2}{*}{ Sex } & Females & 11 & 36.67 & 12 & 60.0 & 23 & 46 & \multirow{2}{*}{$x^{2}=2.63$} & \multirow{2}{*}{0.10} \\
\hline & Males & 19 & 63.33 & 8 & 40.0 & 27 & 54.0 & & \\
\hline \multirow{2}{*}{ HTN } & Positive & 17 & 56.67 & 8 & 40.0 & 25 & 50.0 & \multirow{2}{*}{1.33} & \multirow{2}{*}{0.25} \\
\hline & Negative & 13 & 43.33 & 12 & 60.0 & 25 & 50.0 & & \\
\hline \multirow{2}{*}{ DM } & Positive & 14 & 46.67 & 11 & 55.0 & 25 & 50.0 & \multirow{2}{*}{0.33} & \multirow{2}{*}{0.56} \\
\hline & Negative & 16 & 53.33 & 9 & 45.0 & 25 & 50.0 & & \\
\hline \multirow{3}{*}{ Smoking } & Positive & 7 & 23.33 & 2 & 10.0 & 9 & 18.0 & \multirow{3}{*}{ FET } & \multirow{3}{*}{0.12} \\
\hline & Negative & 17 & 56.67 & 17 & 85.0 & 34 & 68.0 & & \\
\hline & Ex-smoker & 6 & 20.0 & 1 & 5.0 & 7 & 14.0 & & \\
\hline
\end{tabular}

Table 2: Baseline investigations in both groups:

\begin{tabular}{|c|c|c|c|c|c|c|c|c|c|c|c|}
\hline \multirow{2}{*}{ Variable } & \multicolumn{3}{|c|}{$\begin{array}{l}\text { Cases } \\
(\text { no. }=30)\end{array}$} & \multicolumn{3}{|c|}{$\begin{array}{l}\text { Controls } \\
(\text { no. }=20)\end{array}$} & \multicolumn{3}{|c|}{$\begin{array}{c}\text { Total } \\
(\text { no. }=50)\end{array}$} & \multirow[t]{2}{*}{$\mathrm{t}$} & \multirow[t]{2}{*}{$P$} \\
\hline & Mean & $\pm S D$ & Range & Mean & $\pm S D$ & Range & Mean & $\pm S D$ & Range & & \\
\hline Cholesterol & 166.93 & 31.27 & $118-223$ & 158.35 & 28.47 & $114-212$ & 163.5 & 30.18 & $114-223$ & 0.98 & 0.33 \\
\hline TG & 142.83 & 45.2 & $78-211$ & 150.85 & 46.6 & $88-262$ & 146.04 & 45.46 & $78-262$ & 0.61 & 0.55 \\
\hline LDL & 91.45 & 29.39 & $\begin{array}{l}36.4- \\
141.4\end{array}$ & 78.83 & 29.95 & $30-142.6$ & 86.4 & 29.97 & $\begin{array}{c}30- \\
142.6\end{array}$ & 1.47 & 0.15 \\
\hline HDL & 46.87 & 7.88 & $32-58$ & 49.35 & 7.73 & $36-60$ & 47.86 & 7.84 & $32-60$ & 1.10 & 0.28 \\
\hline$E F$ & 60.97 & 8.26 & $41-75$ & 58.4 & 8.57 & $41-71$ & 59.94 & 8.4 & $41-75$ & 1.06 & 0.29 \\
\hline
\end{tabular}

Table 3: Comparison of miRNA-155 expressions between the four quartiles

\begin{tabular}{|c|c|c|c|c|c|c|c|c|c|c|c|c|c|c|}
\hline \multirow{3}{*}{ Variable } & \multicolumn{12}{|c|}{ GENSINI score } & \multirow{3}{*}{ Test } & \multirow{3}{*}{$P$} \\
\hline & \multicolumn{3}{|c|}{$\begin{array}{c}<18 \\
\text { (no. }=7)\end{array}$} & \multicolumn{3}{|c|}{$\begin{array}{c}18- \\
\text { (no. }=8)\end{array}$} & \multicolumn{3}{|c|}{$\begin{array}{c}31- \\
(\mathrm{no}=7)\end{array}$} & \multicolumn{3}{|c|}{$\begin{array}{l}46-126 \\
\text { (no. }=8)\end{array}$} & & \\
\hline & Mean & $\pm \mathrm{SD}$ & Range & Mean & $\pm \mathrm{SD}$ & Range & Mean & $\pm \mathrm{SD}$ & Range & Mean & $\pm \mathrm{SD}$ & Range & & \\
\hline $\begin{array}{l}\text { RQ Micro } \\
\text { RNA }\end{array}$ & 1.24 & 0.47 & \begin{tabular}{|c|}
$0.58-$ \\
1.67
\end{tabular} & 0.66 & 0.2 & $\begin{array}{l}0.41- \\
0.97\end{array}$ & †0.32 & 0.17 & $\begin{array}{c}0.18- \\
0.63\end{array}$ & †0.21 & 0.09 & $\begin{array}{c}0.13- \\
0.38\end{array}$ & $\begin{array}{c}x^{2}= \\
21.58\end{array}$ & $\begin{array}{c}<0.001 \\
(\mathrm{HS})\end{array}$ \\
\hline
\end{tabular}

$\dagger$ Significant differences compared to GENSINI score $<18$

$\ddagger$ Significant differences compared to GENSINI score $18-<31$

Table 4: Correlation between micro RNA 155 and estimated parameters in case group.

\begin{tabular}{|c|c|c|}
\hline Variable $($ no. $=30)$ & Spearman correlation coefficient (rho; $\rho)$ & $\mathrm{P}$ \\
\hline Age (years) & 0.27 & 0.15 \\
\hline Cholesterol & -0.60 & $\begin{array}{c}<0.001 \\
(\mathrm{HS})\end{array}$ \\
\hline TG & -0.39 & $\begin{array}{c}0.03 \\
(\mathrm{~S})\end{array}$ \\
\hline LDL & -0.55 & $\begin{array}{c}0.002 \\
(\mathrm{~S})\end{array}$ \\
\hline HDL & 0.15 & 0.41 \\
\hline EF & -0.02 & 0.89 \\
\hline
\end{tabular}




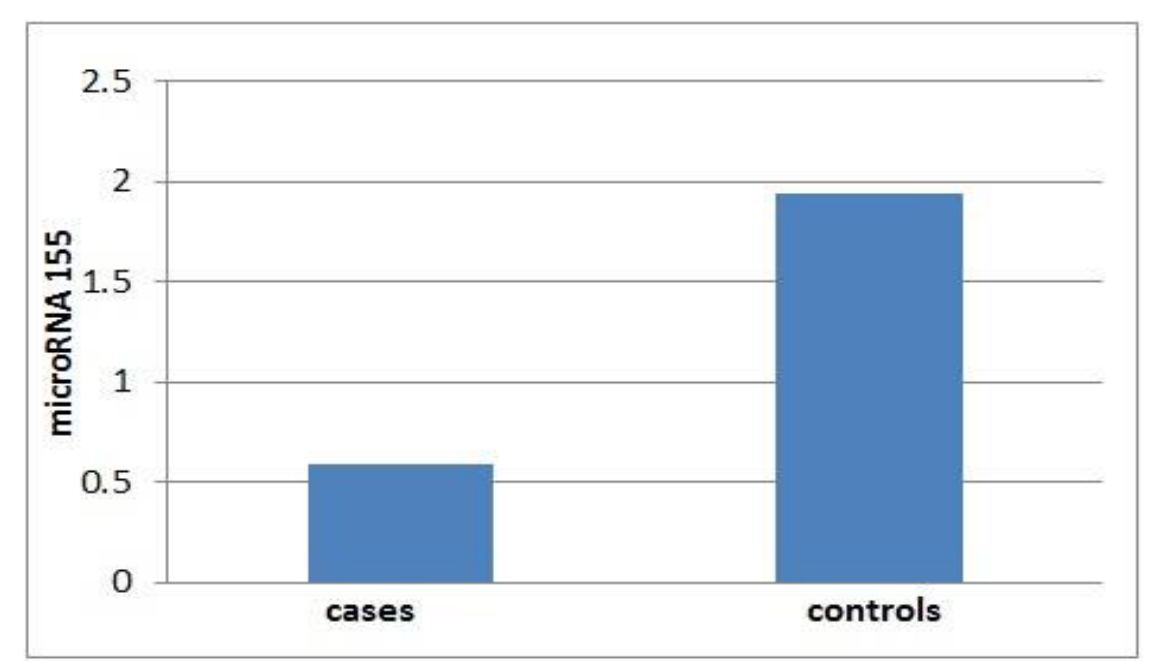

Fig. 1: MicroRNA 155 levels in patients and control groups.

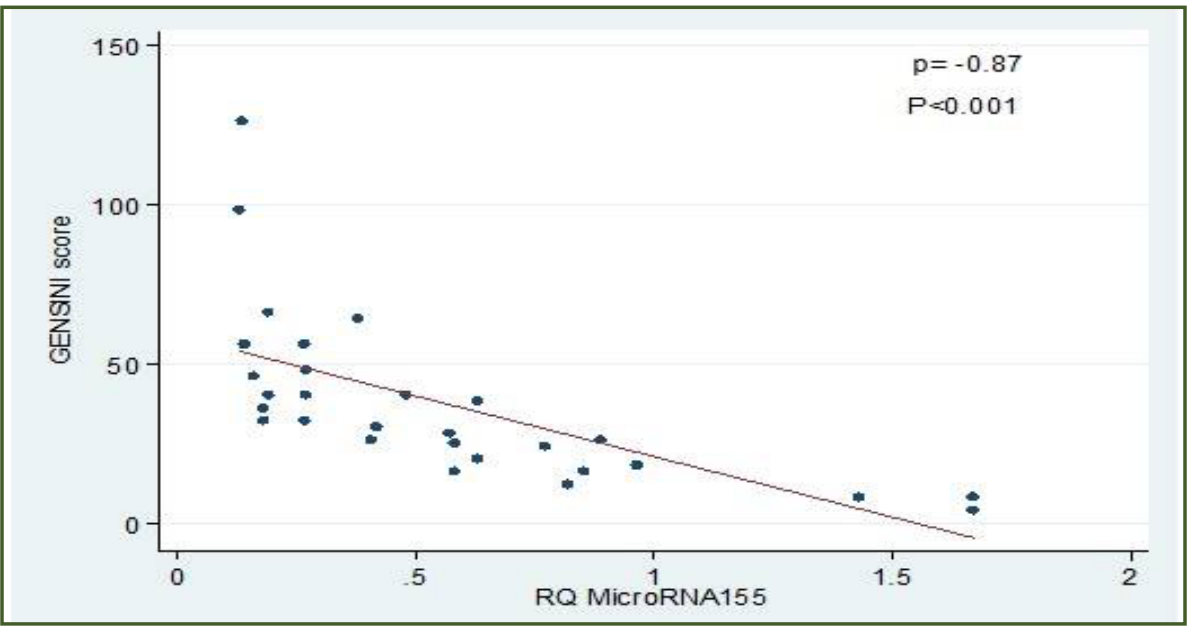

Fig. 2: Correlation between micro RNA 155 and genesis score

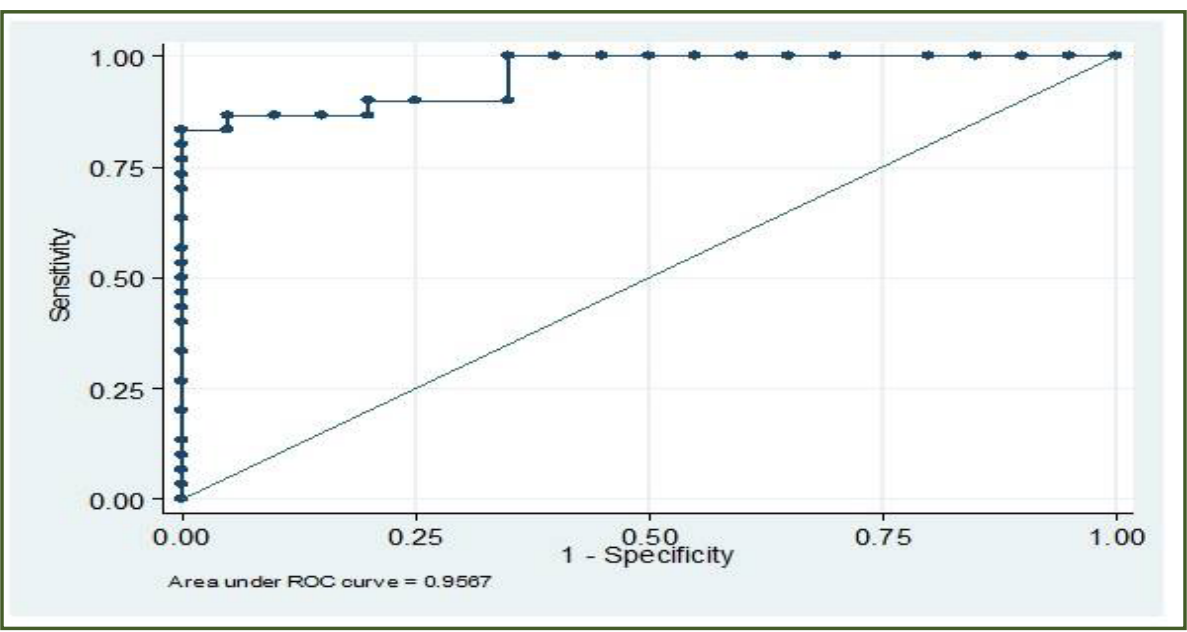

Fig.1 : Roc curve analysis of microRNA 155 for the prediction of severity of coronary atherosclerosis.

http://www.pacificejournals.com/aabs 


\section{Discussion}

Atherosclerosis is a chronic inflammatory disease characterized by lipids and inflammatory cells deposition in the vessels' walls. It is one of the major causes of death worldwide. Inflammation and immune responses play an axial function in all atherosclerotic phases starting from preface of the fatty streak ending in acute coronary syndromes (ACS) eruption ${ }^{2}$.

Micro RNAs (miRNAs) are small non coding RNA molecules linkedto many physiological and pathological conditions, as most of inflammatory processes thorough cardiovascular disease. Through enhancing translation repression or RNA degradation, miRNAs regulate gene expression negatively ${ }^{9}$.

As a multifunctional miRNA, miRNA-155, was implicated in cardiovascular diseases, viral infections, and various types of cancers as it is able to regulate complex pathophysiological processes and to be involved in cardiovascular remodeling, which results in cardiovascular diseases such as coronary artery disease, abdominal aortic aneurysm and heart failure ${ }^{10}$.

Besides, being highly expressed in multiple autoimmune inflammatory diseases and in activated immune cells, miRNA-155 is expressed in different cells, smooth muscle cells, monocyte and macrophages are some examples. In myeloid cells, miRNA-155 expression can be induced by various inflammatory signals, aslipopolysaccharide, tumor necrosis factor and interferon-b. Moreover,miRNA-155 expression in THP-1 macrophages was induced byoxidized low-density lipoproteins (oxLDLs).Increase in the inflammatory stimuli (oxLDLs) uptake and foam cell formation in these cells occured when miRNA-155 was inhibited. As a result, miRNA-155 is considered to be an inflammation-related miRNA ${ }^{11}$.

Aiming to studythe impact of miRNA-155 levels on both the severity and extent of coronary artery stenosis assessed by coronary angiography and the Gensini score, wecompared the relative expression of miRNA-155 in a group of chronic stable angina patients with a normal matched group proved by coronary angiography.

In the present work, we dealt with two groups of patients, a normal control group (20 individuals) and a group of chronic stable angina patients (30 patients). The two groups were matched with no significant difference regarding age, sex, history of hypertension, history of diabetes and history of smoking. Also there was no statistically significant difference between the two studied groups in levels of cholesterol, triglycerides, HDL, and LDL.

In addition, there was no significant difference in ejection fraction between the control group and the stable angina group with a $\mathrm{P}$ value 0.29 . In accordance with our aim, the micro RNA 155 relative quantity was significantly lower in the stable angina group than in the control group.

These results coincides with Fichtlscher et al. ${ }^{12}$ who performed a study designed to assess the suspected prognostic role of micro-RNAsin stable CAD. They studied the miRNA profiles in 16 subjects,only 8 of them were stable CAD patients. All participants received the indicated treatment. The results of the studyrevealed elevation inthe cardiomyocyte-enrichedmi RNAs(miRNA-133 and miRNA-208a) in the patients' group. On the other hand, significant decrease in plasma levels of endothelial cell-enriched (miRNA-126, miRNA-17 and miRNA-92a),vascular smooth muscle cells associated (miRNA-145) and inflammatory cell-enriched (miRNA-155) were observed in the patients' group. Larger study by the sameauthor confirmed those results.

The results of the present study are also in accordance with that of Zhu et al. ${ }^{13}$ who performed a study on 110 patients. In that study, the expression patterns of miRNA-155 in Peripheral blood mononuclear cells PBMCs of the CAD group was significantly lower than that of the non-CAD group and the plasma expression pattern of microRNA-155 were in accordance with the pattern in PBMCs; that it was significantly lower than that of the non-CAD $(\mathrm{P}<0.05)$. The plasma level of miRNA-155 was lower in patients with SAP, UAP, and AMI than in patients with CPS, whereas no statistically significant difference was observed between patients with SAP and CPS.

These results go in line with Zhang et al. ${ }^{6}$ who performed a study to explore the action mechanism of microRNA 155 in atherosclerosis and to study the relationship between miRNA-155 and the severity of CAD and plaque stability. They isolated (PBMC) form blood samples from patients with acute myocardial infarction (AMI), unstable angina (UAP), stable angina (SAP) and chest pain syndrome (CPS) and they found that the expression level of miRNA-155 in blood samples from coronary heart disease patients was much lower than in the blood samples of non-coronary heart disease $(\mathrm{P}<0.05)$ and the miR-155 level in the CPS group was higher than in the SAP, UAP, and AMI groups; the differences were statistically significant.

This result was also approved by D'Alessandro and colleagues, ${ }^{14}$ who found that circulating levels of endothelial-enriched inflammation-associated miRNA-155 are significantly reduced in CAD compared with controls.

As miRNA-155 can be activated by the stimulation of transcription factors in traditional signaling pathways and 
some related factors in other signaling pathways, a feedback mechanism that controls the over-reactivation of immune cells could bethe reason ofmiRNA-155 downregulation ${ }^{15}$.

Also miRNA-155 serves as a negative feedback regulator in OxLDL-stimulated THP-1 inflammatory responses and lipid uptake ${ }^{16}$. Zhang et al. ${ }^{6}$ examined the effort of OxLDL on RAW264.7 macrophage and miRNA-155 overexpression RAW264.7 macrophage. They found that the viability of the cell in miRNA-155overexpression group was much higher than the control groupand the difference was statistically significant $(\mathrm{P}<0.05)$. These results further confirmed that miRNA-155levels declines as CAD progresses and the overexpression of miRNA-155 can inhibit the apoptosis of RAW264.7 macrophage induced by OxLDL.

The important miRNA-155 has multiple functions in endothelial cells, not only in the regulation of inflammation, but also in the inhibition of EC migration in response to Ang II ${ }^{17}$. Also it has been found to directly target endothelial nitric oxide synthase (eNOS) mRNA. Collectively, these data highlight the importance of miR-155 in regulating the inflammatory signaling pathways of the macrophage lineage ${ }^{18}$. However, no difference in miRNA-155 expression in patients with CAD could be detected by Hoekstra et al. ${ }^{19}$, who didn't use coronary angiographies in the assessment of coronary arteries conditionin their study. On the contrary, Wei et al. ${ }^{20}$ performed a study on early stages of atherosclerotic plaques in mice and claimed that upregulation of miRNA-155 is the way to atherosclerosis and the inflammatory stimulation of macrophages via miR342-5p.

Variation inmethods used to analyze the atherosclerotic plaque and different animal models, may be the cause of the conflicting results that obtained by Nazari et al. ${ }^{21}$ who assumed that miRNA-155 enhances atherosclerosis by repressing Bcl6 in macrophages. And they claimed that there is a harmful effect of miRNA-155 on the atherosclerosis process and plaque stability. Correlation studies revealed highly significant negative correlation between miRNA-155 levels and Gensini scores (representing the severity and extent of coronary stenotic lesions) in patients with chronic stable angina $(-0.87, \mathrm{P}$ value $<0.001)$.

We further divided all patients into four quartiles according to the Gensini score. It was found that there was significant downregulation in microRNA 155 (P value $<0.001$ ) among the four quartiles with significant decrease in quartile three and four when compared with the first quartile group and significant decrease in quartile four compared with the second quartile group.
Finding a negative correlation between miRNA-155levels in PBMCs and Gensini score byZhu et al. ${ }^{13}$ who analyzed the correlation between miR-155 levels and Gensini scores($0.663, \mathrm{P}<0.001)$ in all coronary artery disease patients goes in line with our results. And when dividing the coronary artery disease patients into 4 groups according to the number of diseased vessels, they stated that miRNA-155 levels were significantly lower in the patients with two or more diseased vessels compared with those with no diseased vessel $(\mathrm{P}<0.001)$. The relationship between Gensini scores and miRNA-155 in the present study and in other studies suggests that miRNA-155 might have a defensive functionversus atherosclerosisprogression. These results can be indicative of using micro RNA 155 as a marker of severity of atherosclerosis.

In the present study, we applied the Gensini scoring system, instead of number of diseased vessels, to assess the extent and severity of coronary stenotic lesions, because in this system, the coronary trees are divided into 15 segments and even mild lesions are also calculated in the final score ${ }^{22}$.

Onpredicting the severity of coronary atherosclerosis using ROC curve analysis, miRNA-155 shows 86.67\% sensitivity and $80 \%$ specificity with $86.67 \%$ positive predictive value and $80 \%$ negative predictive value and the area under the curve was 0.9567 at the best cutoff point value of 1.43 suggesting that microRNA 155 can act as a marker of severity of atherosclerosis.

When levels of microRNA 155 were correlated with different study variables, it was found that miRNA-155 levels showed significant negative correlation with cholesterol $(-0.60, \mathrm{P}<0.001)$, triglycerides $(-0.39, \mathrm{P}=0.03)$ and LDL levels $(-0.55, \mathrm{P}=0.002)$. These results were in accordance with $\mathrm{Zhu}$ et al. ${ }^{13}$ who found that, miR-155 levels in all patients were negatively correlated with LDL cholesterol $(\mathrm{r}=-0.315)$ although showing positive correlation with total cholesterol. Among many studies investigated the relation between miRNA-155 and coronary atherosclerosis, Zhu et al. ${ }^{23}$ reported that miRNA-155 adjusts the endothelial inflammation and migrationinduced by angiotensin II.

On transplanting bone marrow from a mouse with miRNA-155 -deficiency to a hyperlipidemic one, Donners et al. ${ }^{24}$ discovered that the deficiency of miRNA-155 inhematopoietic cells promoted plaque formation and decreased its stability declaringanatheroprotectiverole of miRNA-155 on atherosclerosis. Zhu et al. ${ }^{25}$ also supported this protective function of miRNA-155 in atherosclerosis and plaque stability. MiRNA-155 was found to be either upregulated or downregulated in coronary artery disease patients and thus might promote or prevent CAD. These 
conflicting results of miRNA-155 in the pathophysiology of atherosclerosis related ischemic heart diseases indicate the complexity of this multifunctional molecule in regulation of cardiovascular remodeling induced by atherogenesis ${ }^{26}$. The cause of this inconsistence might be due to different pathological stages of the disease. Therefore, more studies of underlying mechanisms of miRNA-155 involvement in CAD are needed ${ }^{1}$.

MicroRNAs, these tiny epigenetic silencing phenomena only recently discovered, are moving close to become a realizable diagnostic and therapeutic focus for coronary artery disease (CAD), and the results presented in this study just may have provided supportive data allowing that work to begin in intent on achieving that goal. Wei and colleagues ${ }^{27}$ performed a study on the hypothesis that the effect of miR-155 in macrophages is stage dependent. They found that in early atherosclerosis, miR-155 suppressed macrophage proliferation by targeting colony-stimulating factor-1 receptor and in advanced atherosclerosis, it impaired efferocytosis by downregulating B-cell leukemia/lymphoma 6 . They concluded that targeting the relation between miRNA-155 and B-cell leukemia/ lymphoma 6 might be a promising approach to inhibit the atherosclerosisprogression.

Targetingvariant genes implicated in the same pathway process gives miRNA sapotential therapeutic advantage over traditional therapies as they target a single protein, while unaffected others canpreserve the pathological mechanism ${ }^{28}$. Haveing specific target in the disease pathogenetic mechanism gives miRNAsa high specificity of treatment. Even with weaker power of inhibition,this high specificity, and the long-lasting effect and widespread of action make miRNA modulation a more effective therapy compared to traditional therapy ${ }^{29}$.

The present study supported the protective role for miRNA-155 against the progression of atherosclerosis. Increasing miRNA level sthrough a mimic approach could be now recommended as a considerable therapeutic target. Mimics are double-stranded oligonucleotides containing a (guide strand)identical to the mature miRNA, and a (passenger strand) complementary, or partially complementary strand. The guide strand,loading into the RNA induced silencing complex, act as the endogenous targeted miRNA and block gene expression ${ }^{30}$.

In conclusion, MiRNA-155 was found to be clearly downregulated in studied patients with chronic stable angina. Negative correlation evidenced between miRNA-155 expression and coronarystenotic lesions severityassessed by Gensini scores, boostedthedefensive role of miRNA-155 against atherosclerosis progression.

\section{References:}

1. Cao RY, Li Q, Miao Y, Zhang Y, Yuan W, Fan L. The Emerging Role of MicroRNA-155 in Cardiovascular Diseases. BioMed Research International. 2016; Article ID 9869208 .

2. Getz GS, Vanderlaan PA and Reardon CA. The immune system and murine atherosclerosis. Curr Drug Targets. 2007; 8:1297-1306.

3. Navickas R, Gal D, Laucevičius A, Taparauskaitė A, Zdanyte $\mathrm{M}$ and Holvoet $\mathrm{P}$. Identifying circulating microRNAs as biomarkers of cardiovascular disease: a systematic review. Cardiovascular Research. 2016; 111: 322-337.

4. da-Rocha ER. MicronRNA expression profiles in cardiovascular diseases. BioMed Research International. 2014; Article ID 985408, 23 pages.

5. Vishnoi A and Rani S. MiRNA Biogenesis and Regulation of Diseases: An Overview. In: MicroRNA Profiling Methods and Protocols by Rani S; Springer Science+Business Media New York. 2017; 1-10.

6. Zhang YH, Xia LH, Jin JM, Zong M, Chen M and Zhang B. Expression level of miR-155 in peripheral blood. Asian Pac. J. Trop. Med. 2015; 8: 214-219.

7. Aghili N, Daher E and Carey Kimmelstiel C. Coronary angiography. In cardiology procedures, a clinical primer. By Hendel R. C. and Kimmelstiel C. Publisher: Springer; Chapter 28. 2016;237-248.

8. Gensini GG. A more meaningful scoring system for determining the severity of coronary heart disease. Am J Cardiol. 1983; 51:606.

9. Livak KJ and Schmittgen TD. Analysis of relative gene expression data using real-time quantitative PCR and the 2(-delta delta CT) method. Methods. 2001; 25:402-408.

10. Schober A, Thum T and Zernecke A. MicroRNAs in vascular biology - metabolism and atherosclerosis. ThrombHaemost. 2012;107:603-604.

11. Chen LJ, Lim SH, Yeh YT, Lien SC and Chiu JJ. Roles of microRNAs in atherosclerosis and restenosis. Journal of Biomedical Science. 2012; 19:79.

12. Fichtlscherer S, De Rosa S, Fox H, Schwietz T, Fischer A, Liebetrau C., et al. Circulating microRNAs in patients with coronary artery disease. Circ. Res. 2010; 107: 677-684.

13. Zhu GF, Yang LX, Guo RW, Liu H, Shi YK, Ye JS., et al. microRNA-155 is inversely associated with severity of coronary stenotic lesions calculated by the Gensini score. Coron Artery Dis. Jun. 2014; 25 (4):304-10.

14. D'Alessandra Y, Carena MC, Spazzafumo L, Martinelli F, Bassetti B, Devanna P., et al. Diagnostic potential of plasmatic MicroRNA signatures in stable and unstable angina. PLoS One. 2013;8: e80345. 
15. McCoy CE, Sheedy FJ, Qualls JE, Doyle SL, Quinn SR, Murray PJ., et al. IL-10 inhibits miR-155 induction by tolllike receptors. J Biol Chem. 2010; 285:20492-20498.

16. Huang RS, Hu GQ, Lin B, Lin ZY and Sun CC. MicroRNA-155 silencing enhances inflammatory response and lipid uptake in oxidized low-density lipoproteinstimulated human THP-1 macrophages. J Invest Med. 2010; 58(8): 961-967.

17. Chen LJ, Lim SH, Yeh YT, Lien SC and Chiu JJ. Roles of microRNAs in atherosclerosis and restenosis. Journal of Biomedical Science; 2012; 19:79.

18. Andreou I, Sun X, Stone PH, Edelman ER and Feinberg MW. miRNAs in atherosclerotic plaque initiation, progression, and rupture. Trends Mol Med. 2015; 21(5): 307-318.

19. Hoekstra M, van der Lans CA, Halvorsen B, Gullestad L, Kuiper J, Aukrust P., et al. The peripheral blood mononuclear cell microRNA signature of coronary artery disease. BiochemBiophys Res Commun. 2010;394:792-797.

20. Wei Y, Schober A and Weber C. Pathogenic arterial remodeling: the good and bad of microRNAs. Am. J. Physiol. Heart Circ. Physiol. 2013; 304: 1050-1059.

21. Nazari-Jahantigh M, Wei Y, Noels H, Akhtar S, Zhou Z, Koenen RR., et al. MicroRNA-155 promotes atherosclerosis by repressing Bcl6 in macrophages. J. Clin. Invest. 2012;122: 4190-4202.

22. Alan B, Akpolat V, Aktan A and Alan S. Relationship between osteopenic syndrome and severity of coronary artery disease detected with coronary angiography and Gensini score in men. ClinInterv Aging. 2016; 11:377-82.

23. Zhu N, Zhang D, Chen S, Liu X, Lin L, Huang X., et al. Endothelial enriched microRNAs regulate angiotensin
II-induced endothelial inflammation and migration. Atherosclerosis. 2011; 215:286-293.

24. Donners MM, Wolfs IM, Stöger LJ, van der Vorst EP, Pöttgens CC, Heymans S., et al. Hematopoietic miR155 deficiency enhances atherosclerosis and decreases plaque stability in hyperlipidemic mice. PLoS One. 2012; 7:e35877.

25. Zhu J, Chen T, Yang L, Li Z, Wong MM, Zheng X., et al. Regulation of microRNA-155 in atherosclerotic inflammatory responses by targeting MAP3K10. PLoS One. 2012; 7:e46551.

26. Economou EK, Oikonomou E, Siasos G, Papageorgiou $\mathrm{N}$, Tsalamandris S, Mourouzis K., et al. The role of microRNAs in coronary artery disease: From pathophysiology to diagnosis and treatment. Atherosclerosis. 2015; 241: 624-633.

27. Wei Y, Zhu M, Corbalán-Campos J, Heyll K, Weber C and Schober A. Regulation of Csflr and Bcl6 in macrophages mediates the stage-specific effects of microRNA-155 on atherosclerosis. Arterioscler. Thromb. Vasc. Biol.; 2015; 35: 796-803.

28. Schulte $\mathrm{Z}$ and Zeller T. microRNA-based diagnostics and therapy in cardiovascular disease-summing up the facts CardiovascDiagnTher. 2015; 5(1):17-36.

29. Navickas R, Gal D, Laucevičius A, Taparauskaitė A, Zdanytė $\mathrm{M}$ and Holvoet P. Identifying circulating microRNAs as biomarkers of cardiovascular disease: a systematic review. Cardiovascular Research.2016; 111: 322-337.

30. Laffont B and Rayner KJ. MicroRNAs in the pathobiology of atherosclerosis. Canadian Journal of Cardiology. 2017; 33: 1-170.

*Corresponding author:

Jehan H Sabry, Asisstant professur of Clinical and Chemical Pathology , Faculty of Medicine, Benha University, Egypt

Email: jehanrayan@yahoo.com 